\title{
REINVENCIÓN DE UN GÉNERO: NOVELA NEGRA Y TERRORISMO REINVENTING A GENRE: ROMAN NOIR AND TERRORISM
}

\author{
MIRIAM LÓPEZ SANTOS \\ Universidad de León
}

\begin{abstract}
Resumen
Los asesinos ocultos de 2006, novela escrita por el británico Robert Wilson y que relata la explosión en un edificio de Sevilla a manos de un grupo terrorista, es uno más de tantos intentos de aproximación al conocimiento del fenómeno del terrorismo, pero, al propio tiempo, puede ser empleada de modo paradigmático para explicar la trasgresión que sufre la fórmula de la novela negra, dentro de la posmodernidad, al insertar el terrorismo como motivo narratológico. Se analizarán una serie de elementos que constatan esta afirmación y abren el camino para nuevos estudios ligados a la trasgresión genérica. Palabras claves: novela negra, terrorismo, terror, miedo.
\end{abstract}

\begin{abstract}
The Hidden Assassins (2006), a novel written by the british author Robert Wilson, tells the story of a explosion in a Seville building at the hands of a terrorist group, is one more of many attempts of approaching to the knowledge of the terrorist phenomenon, but, at the same time, can be used in a paradigmatic way to explain the transgression suffered by the crime novel, within the postmodernity, when using terrorism as a narratological motive. A series of elements that validate this affirmation and open a path for new studies linked to generic transgression.
\end{abstract}

Key words: Hard-boiled, terrorism, terror, fear.

"Cuando no hay certezas a las que agarrarse, afirma el inspector Falcón, la tragedia aporta credibilidad" (Wilson, 2007: 400). En efecto, en una Europa devastada, que llora por la gloria perdida, una Europa que se sabe en ruinas y en la que la verdadera crisis se materializa, ya no en la falta de fe en el Estado, ni en la pérdida de horizontes políticos, ni siquiera en la carencia de referentes de modelos económicos, sino en la inexistencia de valores, la única salida posible parece la unión del pueblo ante el mal y su manifestación primera, la tragedia. La novela negra, como subgénero histórico, mira hacia el individuo y su problemática, recoge el sentir del pueblo y lo acaba convirtiendo en principio estético . Por ello, plasma a la perfección esta idea de frustración y desencanto, a través de un retrato pormenorizado de una sociedad y por extensión de un ciudadano en continua crisis, en una búsqueda constante de sí mismo. La pérdida de referentes lo deja en una situación de desamparado, fundamentalmente 
existencial, desde la cual observa perplejo, bajo el yugo del miedo, cómo la maldad prevalece y acaba por apoderarse de todo. Es aquí, entonces, donde el papel del miedo resultará fundamental pues, aunque paraliza al hombre, también lo obliga a actuar.

Los atentados del 11 de septiembre de 2001 en Nueva York supusieron un cambio en la mentalidad occidental que habría de afectar a diferentes ámbitos de la vida. Sus consecuencias cambiaron drásticamente el rumbo de la historia y condujeron a la formación de un nuevo orden mundial. Con posterioridad, los atentados del 11 de marzo de 2004 en Madrid y los del 7 de julio de 2005 en Londres acercaron aún más la tragedia terrorista también a los europeos y nació la cultura del terror . "Cuando esos aviones impactaron en las Torres Gemelas todo cambió" (Wilson, 2007: 322), confirma, contundente Robert Wilson en palabras del Inspector Falcón. Y todo cambió a nivel político, social, cultural o religioso, pero también en la esfera literaria . El terrorismo, como motivo literario puede rastrearse en la historia de la literatura europea desde el siglo XIX, los teóricos apuestan por la intervención en escena de los explosivos como fecha determinante. Sin embargo, la reflexión intelectual y artística sobre la esencia de estos acontecimientos, de su alcance y de sus consecuencias, irrumpe con fuerza en la literatura europea especialmente a partir de aquel fatídico 2001. Subgéneros históricos como la novela negra adoptan el motivo hasta tal punto que acaba modificando sus características y ayudando, al propio tiempo, a prefigurar el esquema de experiencias, respuestas y actuaciones ante un fenómeno de semejante envergadura. Pues los géneros populares, no lo olvidemos, funcionan como redes cognitivas que absorben lo que preocupa a la sociedad del momento, no pueden mantenerse al margen sino que convergen y se retroalimentan de la realidad enriqueciendo la estructura formulaica. Se generan patrones de significado que se repiten en las novelas modificando el género. La novela negra se convierte, así, en una respuesta al fenómeno global del terrorismo, dando lugar a una estética distintiva. Los asesinos ocultos de 2006, novela escrita por el británico Robert Wilson y que relata la terrible explosión en un edificio de Sevilla a manos de un grupo terrorista, puede ser empleada de modo paradigmático para explicar la trasgresión que sufre el género una vez que se inserta dicho motivo.

La comprensión de su complejidad y el cambio de perspectiva aportado a la novela negra exige, sin embargo, una reflexión previa sobre la categoría estética del miedo, en la que se inserta este tipo de terror. La principal alteración de la fórmula negra tiene que ver con la consideración del miedo como categoría estética que se escinde en dos vertientes: el terror y el horror, delimitados por teóricas como Iris Zavala (1995). Se complementan pero desde el siglo XVIII presentan dos formas contrarias de enfrentarse y ver el mundo. No obstante, pasado por el filtro de este fenómeno e inserto en el seno de la novela negra adquiere una nueva perspectiva. Mientras el terror, en origen, se materializaba en cualquier novela a través del suspense, el horror tenía que ver con el lado más perverso del ser humano, con las consecuencias a actos ilógicos y perturbados. El horror posmoderno, es un acto externo, es la materialización primera del miedo. Es palpable, es visible y genera repugnancia. El terror, en cambio, es intrínseco; supone la desesperación, la angustia, el desasosiego, pues es lo que nos imaginamos lo que nos perturba, no lo que vivimos. El terror es ansiedad, inquietud, 
consternación. Proyecta la inseguridad, la falta de referentes, el derrumbe de lo establecido, de lo cotidiano. Por ello, el terrorismo tiene que ver con el terror en tanto que es una experiencia interiorizada y expandida que da el salto del individuo a la colectividad y no tiene límites.

La novela negra europea de las últimas décadas individualizaba el mal en figuras perturbadas, capaces de las mayores atrocidades. La individualización se difumina en estas novelas en una población que se escinde en nosotros y "los otros". Ya no importa el por qué ha sucedido pues la realidad es que sigue sucediendo. Los terroristas no representan a nadie concreto, individualizado, sino a una idea que el terrorismo como fenómeno deja a la imaginación de los que lo experimentan. El individualismo se diluye en la cadena y se convierte en la generalidad de la idea. El terror busca expandirse porque se nutre de la popularidad, mientras el horror queda oculto dado que se relaciona con los actos más abominables del ser humano. Los asesinos de las novelas nórdicas, por ejemplo, se confundían entre la población y sus crímenes obedecían a un estado de perturbación. El horror venía determinado por actos horribles y que a ojos del lector resultan repulsivos.

Asumida la diferencia entre terror y horror, la reacción que sentimos ante la contemplación de lo sucedido supone asimismo una nueva perspectiva que se introduce en la novela negra. El horror se queda congelado en la mente del lector y pasa a formar parte de su imaginario, pues reflexiona sobre la capacidad del ser humano de cometer atrocidades, la falta de valores se materializa en un hombre abandonado a sus instintos más bajos y primarios. En este sentido, las largas escenas de continuadas agresiones, como las que en la citada novela sufre Inés, la mujer del comisario Calderón, las sesiones de tortura interminables, los crímenes más abominables funcionarían como recurso estético. Ya no hay censura, la violencia se muestra con todo su colorido y la muerte o la crueldad no se intuyen, se manifiestan y el ser monstruoso reaparece ante los ojos del lector en toda la complejidad del horror. "la sangre se había extendido debajo y a la derecha de la mesa. Era viscosa y parecía engullir las patas de la silla y la mesa. Refulgía de un modo tan horrible que le palpitaba en los ojos, como si aún tuviera vida" (Wilson, 2010: 278). La escena de Inés yaciendo a los pies de calderos resulta abominable. Sin embargo, es posible contemplarla, asistir al horror y volver de nuevo a la rutina ordinaria. Puede provocar reacciones, lo percibimos como terrible, nos altera, nos perturba, pero es posible el distanciamiento. Nosotros no somos "eso". Estamos al margen No nos afecta. El terror, por el contrario, es una sensación que se apodera de nosotros y acaba condicionando nuestros actos, pues supone una amenaza constante porque no atiende a límites. No es posible presenciar un acto de terror sin pensar en las consecuencias que este acarrea.

Silencio mientras los hombres y mujeres de la policía científica contemplaban su hallazgo. Falcón sentía cómo las mentes de todos los que estaban allí dentro avanzaban hacia conclusiones cada vez más y más inquietantes. Cada atrocidad terrorista islámica había desatado nuevas cepas víricas de terror dentro del organismo de Occidente. En cuanto Occidente se hacía a la idea de que los hombres podían poner bombas, tenía que aceptar que también podían ser las mujeres, e incluso los niños. Ahora parecía espantosamente obvio que de los coches bombas se había pasado a utilizar los barcos y luego los aviones. Al final las atrocidades ya no se circunscribían 
al Oriente Próximo o Lejano o Estados Unidos, sino que habían llegado a Madrid y Londres [...] ¿Cómo va a pensar una mente normal bajo estas condiciones de fácil contagio? (Wilson, 2010: 314).

Y es precisamente ese fácil contagio, esa multiplicación del terror lo que se desprende de las palabras de Fernando Alanis, uno de los vecinos del bloque derruido:

Yo vivo... quiero decir vivía, en un piso horrible en un edificio muy feo, rodeado de otros edificios muy feos. Pocos de los que vivimos allí tenemos coches. Pocos vamos de vacaciones. Muchos no llegamos a fin de mes. Y somos nosotros los que vivimos con los marroquíes y otros norteafricanos. Soy una persona tolerante. He de serlo. Trabajo en obras donde hay mucha mano de obra barata, inmigrante. Respeto el derecho de la gente a creer en el dios que les dé la gana, y a ir a la iglesia o mezquita que le dé la gana. Pero desde el 11 de marzo de 2004 me he vuelto suspicaz. Desde ese día, en el que 191 personas murieron en esos trenes, me he preguntado dónde sería el próximo atentado. No soy racista y sé que los terroristas son un ínfimo porcentaje de una gran población, pero el problema es que... no sé quiénes son. Viven conmigo, viven en mi sociedad, disfrutan de su prosperidad, pero un día decidieron poner una bomba en mi edificio y matar a mi mujer y a mi hijo. Y somos muchos los que desde el once de marzo hasta este último seis de junio hemos vivido en un estado de sospecha y temor" (Wilson, 2010: 333-334).

Ellector, como el personaje, pierde su seguridad. El terror suponela radicalización y la inseguridad a todos los niveles pues el terrorismo puede provenir de criminales, de gobiernos corruptos, de la política, de movimientos religiosos y su puesta en práctica pude afectar, del mismo modo, a muchas esferas, desde la guerra, a la rebelión, la resistencia, la opresión o la protesta y con la intención de desestabilizar o destruir el sistema, provocar en la población la psicosis descontrolada o crear un nuevo orden. Es lo que le sucede al inspector Falcón. Una vez perpetrado el atentado terrorista, la existencia de una mezquita cerca del lugar del siniestro enciende las alarmas y, tanto la policía como la población sitúa a los grupos islamistas en el punto de mira. Falcón sospecha, sin embargo, que la conspiración es mucho más compleja. Y no se equivoca. Detrás del atentado hay una complicada trama que esconde la participación de grupos islamistas, pero también de otro tipo de organizaciones con ideas igual de fanáticas. La experiencia de terror que experimenta el personaje puede observarse a través de las palabras del narrador:

El cielo se había vuelto púrpura sobre el casco viejo, como la decoración en torno a una herida reciente que hubiera empezado a doler en serio. Falcón conducía de forma automática, la mente absorta en problemas insolubles: una bomba explota, mata, mutila y destruye. Lo que queda cuando se disipa el polvo y se retiran los cadáveres es una horrenda confusión social y política, en la que las emociones afloran, $\mathrm{y}$, al igual que el viento sobre la hierba de la pradera, su influencia puede crear extrañas alucinaciones en la gente (Wilson, 2010: 171).

Sin embargo, esta falta de certezas, esta terrible incertidumbre adquiere proporciones inimaginables de la mano de un elemento que no puede faltar en estas novelas: los medios de comunicación de masas. La idea de terror queda materializa en el papel que cobran los medios de comunicación de masas . Los periodistas aparecen dibujados como iconos de esa ausencia absoluta de valores. Provocan todo tipo de reacciones y su propagación del terror no tiene límites. Son personajes crueles, cuya única intención es la manipulación, que obedece no solo a intereses económicos, sino ideológicos. Se trata de las primeras piezas de un puzle que, llevado a término, 
supondrá un nuevo orden. Se convierten en elementos imprescindibles en la historia, pues su aparición siempre se vincula a instantes especialmente críticos, de terror exacerbado, por el revuelo que causan en la opinión pública.

Javier estaba echado en la oscuridad, con las imágenes de las últimas noticias aún en su mente: el edificio demolido bajo el resplandor quirúrgico de los focos; los escaparates rotos de algunas tiendas de productos marroquíes, los bomberos apagando un piso en llamas al que unos jóvenes habían arrojado un cóctel Molotov; un muchacho marroquí con la cara hinchada, llena de cortes y moratones, al que unos neonazis habían apaleado con palos y cadenas, un carnicero que vendía carne halal en cuya puerta metálica habían estrellado un coche. Falcón apartó aquellas imágenes de su mente hasta que solo quedó un último residuo de terror: la profunda incertidumbre (Wilson, 2010: 209).

De hecho, irrumpen en la trama argumental en los momentos clave de la investigación e incluso determinan los pasos a seguir por la policía. Al ABC llega la carta de Abdulá Azzam reclamando el acto terrorista, la televisión difunde las primeras imágenes del padre que ha perdido a su mujer e hijo y espera a su hija superviviente en el hospital, la prensa habla por primera vez de atentados provocados por fundamentalistas islámicos, por las imágenes que se observan en el televisor de un bar percibimos el estado de perturbación y de odio que se ha generado en la población e, incluso, el final de la novela descubrirá que el atentado estaba directamente relacionado con uno de los comunicadores más famosos e influyentes de Sevilla, Ángel Falcón. No interesa la veracidad sino, y como leemos en las páginas de la novela, "el drama, la emoción y una superficie brillante por debajo de la opacidad" (Wilson, 2010: 363). A consecuencia de su procedimiento y como responsables directos e indirectos de generar el caos, la posición de los medios de comunicación es duramente criticada a lo largo de la novela.

En estrecha relación con esta estética del terror encontramos otra de las características que imperan en este tipo de novela negra. Frente a posturas actuales más líricas, las nórdicas (López Santos 2013), o más sórdidas, las mediterráneas, la novela bajo el tamiz del terrorismo, recupera todas las dosis de realismo y vuelve a aparecer enlazada con la tendencia de novela negra cultivada a mediados del siglo XX. En este caso es el terror y la necesidad de ser transmitido al lector, como elemento constitutivo de la trama, el que exige la sensación de realidad. El escenario del atentado es descrito con toda precisión y sin dejar ningún detalle al margen, pues la identificación del grupo terrorista requiere minuciosidad y exactitud, por parte de la policía pero también por parte del narrador. El bloque de pisos de El cerezo, las casas, la guardería y la mezquita como zona cero de la explosión se convierten en un escenario distópico que puede ser rastreado a la perfección en su homónima, la Sevilla real. Ventanas, pisos, calles, bancos, coches, suponen una información desmedida que el lector necesita, pero que apenas es capaz de procesar por lo que precisa volver sobre lo leído para ordenar la escena. La sensación que obtiene es de realidad pero también de desproporción. Se trata de una estética del exceso motivada por la necesidad de dar explicación al terror, pero también como consecuencia primera del mismo. Una técnica que determina el relato y se alza como otro de los elementos constitutivos de su fórmula.

Junto al espacio el tiempo también contribuye a la sensación de realidad, por un lado, y de exceso, por otro. Tiempo y espacio se necesitan porque todo sucede en 
algo más de un mes. La importancia del tiempo queda fijada en los días y las horas, que se detallan como títulos introductorios a cada capítulo: el día y la hora exacta, desde un 6 de junio de 2006, 2:00 horas hasta el 10 de junio de 2006. Además se insiste continuamente en la falta de horas de sueño de los investigadores, en los sucesos que transcurren al mismo tiempo en lugares diferentes, en definitiva, en la sensación de tiempo robado. "La saturación de cada minuto, no solo con sus hallazgos, sino con las ramificaciones de las investigaciones paralelas que llevaban a cada una gran cantidad de agentes por toda España, Europa, y el mundo, hacían que cada hora pareciera un día entero" (Wilson, 2010: 268). Una impresión que destaca aún más si se compara con los personajes que se mantienen al margen del atentado, atentado que acabará afectándolos y determinando sus actos. Porque nadie puede escapar al terror, nadie. En las sesiones de Consuelo en el psicólogo, el ritmo frenético de la investigación se ralentiza y el lector siente la sensación de descanso. Sin embargo, apenas dura unas páginas y, al final, su realidad y la que vive la población acaban siendo una sola.

Frente al caos mediatizado y generalizado, el detective Falcón aporta a la historia el único punto de racionalidad. A pesar de que aparece dibujado como un personaje complejo, en cierta medida desamparado y solitario, algo perdido y desconcertado, y con una problemática motivada por sus relaciones personales no será su crisis interna el aspecto que determine su carácter. La tendencia introspectiva predominante en la novela negra europea posmoderna, que acababa por descubrir seres profundamente perturbados, pasa a un segundo plano en beneficio de la razón, entendida esta no en el sentido clásico del término, a lo Sherlock Holmes, sino por su proximidad a la ética. En una Sevilla que duda de sus ciudadanos, que desaloja edificios, vacía calles y se enclaustra en sus viviendas, que paraliza el tráfico aéreo, pero también el mercado inmobiliario; en una Sevilla multicultural que acaba por rechazar lo extranjero aunque forme parte de su idiosincrasia, la cordura aparece representada en el policía Javier Falcón, descrito desde su marcada humanidad, su indeleble profesionalidad y un hondo sentido de la justicia. A Robert Wilson le interesa su condición de doble, sevillano con familia musulmana, hablante de español y de árabe, conocedor de costumbres a este y al otro lado del mediterráneo. Un aparente caos que se torna en racionalidad. Será su visión amplia, libre de prejuicios, al margen de la mediatización la que le sitúa en una posición ideal para valorar el alcance del atentado, sus consecuencias y la veracidad de lo vivido. Es preciso para mantener la coherencia interna de la novela negra un detective con carácter sólido, que se mantenga firme ante la manipulación, de lo contrario la novela se perdería en una suerte de divagaciones sobre el fenómeno del terrorismo, su alcance y sus consecuencias.

En definitiva, y ya para finalizar, a través del análisis de la novela Los asesinos ocultos de Robert Wilson he pretendido justificar cómo la visión del terrorismo, inserta en la novela negra europea, provoca una nueva interpretación del género, lo trasgrede, lo reactualiza y lo vincula a la realidad. Así, la fórmula de la novela negra sufrirá diferentes variaciones siempre dentro de la posmodernidad y precisamente debido a la misma, al tiempo que se convierte en uno más de tantos intentos de aproximación al conocimiento del fenómeno del terrorismo y ello a pesar de que, como le dice el agente 
del CNI Mark Flowers a Javier Falcón, “No intentes comprender todo el conjunto... no hay nadie en el mundo que lo consiga" (Wilson, 2010: 204).

\section{BIBLIOGRAFÍA}

Amorós , A. (1979): Introducción a la literatura, Madrid, Castalia.

Domingo i Valls, A. (2008): Descenso literario a los infiernos demográficos, Barcelona, Anagrama.

Frank, M. C., Gruber Rodopi. E. (2012): Literature and Terrorism: Comparative Perspectives, New York, Rodopi.

Herrerín López, A. (2008): El nacimiento del terrorismo en Occidente, Madrid, Siglo XXI Editores.

Lippmann, W. (2003): La opinión pública. Madrid, Langre.

López Santos M. (2013): “El cine negro en los Países Nórdicos” en Novela y cine negro en la Europa actual (1990-2010). Editorial Biblioteca Nueva, 245-268.

Roiz, M. (2005): Sociología de la comunicación y cultura de masas. Madrid, Ediciones del Laberinto.

Wilson, R. (2010): Los asesinos ocultos, Madrid, RBA Libros.

Woff M. (2000): La investigación de la comunicación de masas. Crítica y perspectivas. Barcelona, Paidós.

Zavala, I. (1995): “Erotismo y terror; el fantasma del texto o cuando los espejos tienen manchas", en España Contemporánea: Revista de Literatura y Cultura, Tomo 8, 2, 117-128. 